\title{
A Register-Based Study of Occupational Functioning in Non-Psychotic Patients Before and After Psychotherapy
}

\author{
Morten Fenger ${ }^{*}, 1$, Stig Poulsen ${ }^{2}$, Erik Lykke Mortensen ${ }^{3}$ and Marianne Lau ${ }^{1}$ \\ ${ }^{I}$ Stolpegaard Psychotherapy Centre, Mental Health Services, Capital Region of Denmark, Denmark \\ ${ }^{2}$ Department of Psychology, University of Copenhagen, Denmark \\ ${ }^{3}$ Institute of Public Health and Center for Healthy Aging, University of Copenhagen, Denmark
}

\begin{abstract}
Background: Mental disorders are an important cause of occupational impairments. Little is known about whether psychotherapeutic treatment helps patients function in their jobs. This study investigated long-term changes in occupational functioning for patients referred to treatment.

Method: We recruited 747 consecutive patients and 14,940 matched control subjects. Data on days on sick leave, unemployment and disability pension were collected for 2002-2007 from central registries and analyzed.

Results: Of the 747 patients, 216 did not show up for treatment and 531 completed treatment. Patients who completed treatment (completer patients) had, on average, 15.7 days on sick leave two years before treatment and 23.1 days on sick leave two years after treatment, while the control group had 5.4 and 7.5 days, respectively. Regarding disability pension, completer patients had 7.6 days before and 14.9 days after treatment, while the control group had 7.8 and 11.0 days, respectively. Regarding unemployment completer patients had 13.9 and 10.1 days, while control group had 9.0 and 8.3 days, respectively. The analysis of covariance (ANCOVA) showed that completer patients had a significantly higher number of days on sick leave $(p<0.001)$ and disability pension $(p=0.010)$ compared to the control group, while the change in days with unemployment was insignificant $(p=0.501)$.

Conclusion: Occupational outcome of psychotherapy may be less advantageous than shown in previous studies. Differences can perhaps be explained by the length and symmetry of the observation period before and after intervention. Other possible reasons for the outcome are: disorder chronicity; a labor market that excludes individuals with mental disorders; and that psychotherapy does not address occupational functioning.
\end{abstract}

Keywords: Psychotherapy, registries, occupational status, absenteeism, outcome.

\section{INTRODUCTION}

Mental disorders have a serious impact on occupational functioning and are one of the primary causes of sick leave $[1,2]$. In addition to being associated with an increased risk of unemployment [3], mental disorders are also one of the main reasons why disability pensions are granted $[1,4,5]$. In Sweden, mental illness caused $23 \%$ of all long-term sick leave days [1]. Furthermore, according to statistics from the OECD, people diagnosed with a mental disorder receive $35 \%$ of all disability pensions in Europe [4].

Over the decades, psychotherapy has been thoroughly researched concerning its impact on symptoms [6], and meta-analytical studies have confirmed that psychotherapeutic treatment is effective in relieving symptoms [7], though some studies show that psychotherapy is not necessarily associated with a reduction in the utilization of health care services [8,9]. Nevertheless, the impact of psychotherapeutic treatment on the occupational functioning

*Correspondence address: Nørre Alle 21, 4 tv, DK-2200, Denmark;

Tel: +0045 61665755; E-mail: Morten.Fenger@.regionh.dk of patients (sick leave, unemployment and disability pension) has only been researched sparsely $[5,10,11]$, even though the potential economic gains are high $[2,12]$.

In a review, Mintz et al. found that psychotherapy significantly improved occupational functioning assessed with the Social Adjustment Scale (SAS) for patients with depression [13], but another review did not find that intervention had a significant effect on occupational functioning [14]. We identified nine studies on intervention for non-psychotic mental disorders measuring sick leave absence and found that they all reported that psychotherapy led to a reduced number of sick leave days [9,15-22]. The most recent study, conducted by Linden et al., investigated 44 patients treated with cognitive behavioral therapy for anxiety disorders. During the eight months prior to intake, the patients had an average of 3.1 sick leave days per month (the equivalent of 37.2 days per year), whereas the average was only 1.1 days per month in the eight months after treatment (equals 13.2 days per year) [22].

According to the literature, there are only a few studies investigating whether or not psychotherapeutic intervention improves the ability to obtain and/or maintain a job for 
patients with non-psychotic mental disorders [11,23], or if specialized intervention programs programs aimed at improving employment stability are needed [24-28]. Studies investigating the impact of psychotherapeutic interventions on the risk of obtaining disability pension due to nonpsychotic mental disorders are also sparse $[2,5]$. The available studies merely confirm that anxiety and depression are associated with a higher risk of being awarded disability pension $[29,30]$ and disability pension, in many cases, is preceded by a long period of sick leave $[31,32]$.

The studies measuring the occupational functioning associated with psychotherapeutic intervention have certain methodological weaknesses: First, the nine studies on sick leave referred to above compare occupational functioning at the time of intake, when mental illness is likely to be particularly severe, with functioning at various points after the end of treatment. Here, a larger decrease in days with work dysfunction would then be expected compared to a study that averaged longer, symmetrical time periods before and after treatment. Second, few studies used a non-mentally affected control group when taking development and change in the labor market into account, thereby neglecting that rates of employment and disability pension are influenced not only by individual characteristics, but also by the state of the labor market and political regulation [5,32]. Third, several studies used patient self-reporting, which has been shown to deviate from administrative data [33]. Fourth, most studies investigated sick leave, unemployment and disability pensions separately, even though these three parameters are interdependent $[2,31,32]$. Consequently, access to reliable data is necessary in order to accurately measure occupational outcomes, and in Denmark this is possible because all social security benefits and social welfare pension payments are meticulously recorded in administrative registries.

The aim of this study is to investigate the long-term outcome of psychotherapy in non-psychotic patients on occupational functioning in terms of the number of days with sick leave, unemployment and disability pension and to evaluate the association between treatment status (completer patients and no-show patients) and occupational functioning compared to a matched control group.

\section{MATERIALS AND METHODOLOGY}

\section{Setting}

The Stolpegaard Psychotherapy Centre, Mental Health Services, Capital Region of Denmark, provides treatment for adults with non-psychotic mental disorders, including mood disorders, neurotic disorders, behavioral syndromes (i.e. eating disorders) and personality disorders. The Centre offers outpatient $(80 \%)$ and inpatient $(20 \%)$ treatments in a fiveday care unit, primarily using group psychotherapy. The Centre offers cognitive behavioral group therapy for patients with anxiety and depression, systemic and narrative group therapy for patients with eating disorders, and psychodynamic group therapy for patients with personality disorders. Inpatient treatment also includes milieu therapy. Short-term individual therapy is offered to patients unsuited for group therapy for a mean of 10 sessions. The typical group therapy format is $16-20$ sessions, with $2.5 \mathrm{hr} / \mathrm{session}$. The Centre does not employ psychotropic treatment.

\section{Definitions of Treatment Status}

No-shows are patients who came to the assessment interview and were offered treatment, but did not show up for their first and later treatment sessions and did not attempt to change the appointment or notify the centre. Completers are patients who started their treatment and participated in the full program or had more than six sessions and stopped under consultation with the therapists. Drop-outs are patients who started their treatment, but stopped treatment without consulting with the therapists. Drop-out patients are not included in this study.

\section{Patient Sample}

Nine-hundred and forty-four consecutive patients referred to and offered psychotherapeutic treatment at Stolpegaard Psychotherapy Centre from January 1, 2004 to December 31, 2005 were eligible for the study. A priori, drop-out patients $(\mathrm{n}=102)$ were excluded to avoid inclusion of patients who clearly were neither no-shows nor completers. It was also decided a priori to exclude 81 patients of non-Danish origin to avoid problems in matching with controls. Fourteen patients could not be identified in the administrative registries. In all, 747 consecutive patients were included in the study (see Fig. 1 for sample disposition and Table 1 for demographic and diagnostic data). The first patient in the study was assessed on January 5, 2004 and the last patient completed treatment on December 29, 2005.

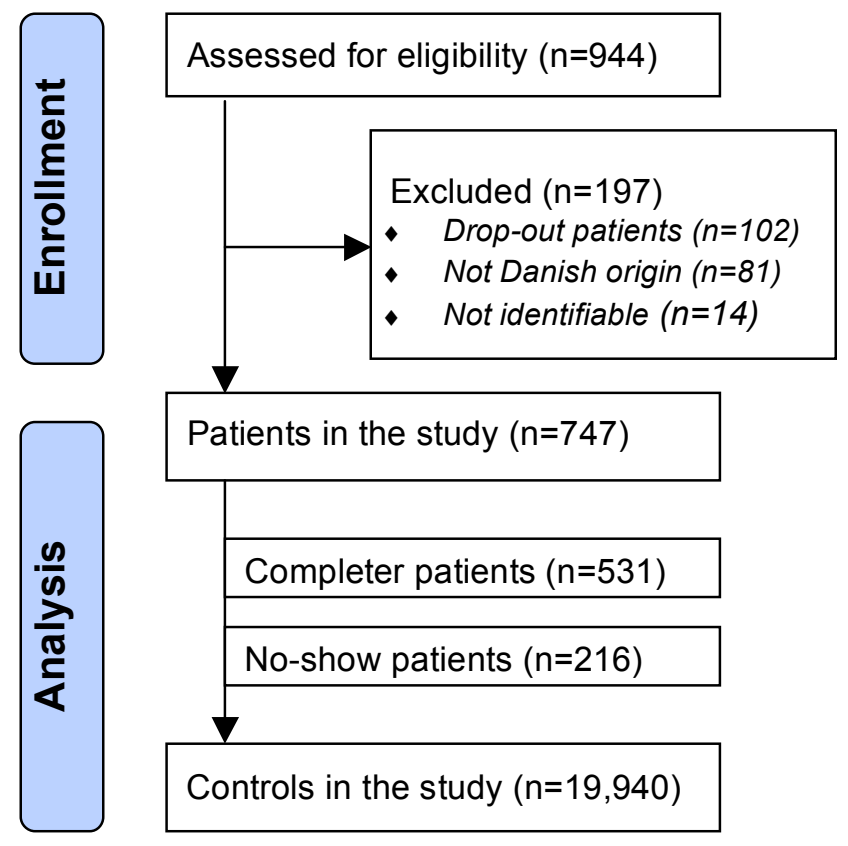

Fig. (1). Sample disposition.

\section{Control Sample}

We included a matched control group as a comparison group for the natural development in sick leave, unemployment and disability pension. For each patient, we randomly collected and matched 20 control individuals from the Central Population 
Table 1. Demographic and Diagnostic Data

\begin{tabular}{|c|c|c|c|c|c|c|c|}
\hline & $\begin{array}{c}\text { Female/Male } \\
(\text { Female \%) }\end{array}$ & Age (SD) & $\begin{array}{l}\text { Mood Disorders } \\
\text { F30-39 (\%) }\end{array}$ & $\begin{array}{c}\text { Neurotic } \\
\text { Disorders } \\
\text { F40-49 (\%) }\end{array}$ & $\begin{array}{l}\text { Behavioral } \\
\text { Syndromes } \\
\text { F50-59 (\%) }\end{array}$ & $\begin{array}{c}\text { Personality } \\
\text { Disorders } \\
\text { F60-69 (\%) }\end{array}$ & $\begin{array}{l}\text { Missing Data* } \\
\text { (Controls: } \\
\text { No Diagnosis) }\end{array}$ \\
\hline Completer $(\mathrm{N}=531)$ & $431 / 100(81 \%)$ & $33.4(10.8)$ & $119(22 \%)$ & $235(44 \%)$ & $101(19 \%)$ & $64(12 \%)$ & $12(2.3 \%)$ \\
\hline No-shows $(\mathrm{N}=216)$ & $176 / 40(81 \%)$ & $31.1(10.3)$ & $35(16 \%)$ & $110(51 \%)$ & $34(16 \%)$ & $31(14 \%)$ & $6(2.8 \%)$ \\
\hline Control $(N=14,940)$ & $12,140 / 2,800(81 \%)$ & $32.7(10.6)$ & $24(0.16 \%)$ & $38(0.25 \%)$ & $10(0.07 \%)$ & $22(0.15 \%)$ & $14,846(99.4 \%)$ \\
\hline
\end{tabular}

Register in Denmark based on four criteria: (1) Danish ethnicity, (2) resident in same geographic area, (3) same sex, and (4) same date of birth. A total of 14,940 control subjects were included. No exclusions were made.

\section{Design}

Designed as a matched control pre-post study, each patient was matched to a group of 20 control subjects. We obtained data on the annual number of registered days with sick leave beyond 14 days, unemployment, and disability pension for individual patients and the matched control subjects from 1 January 2002 to 31 December 2007. For all patients, the study covered register data over a five-year period that included a two-year pre-intervention period, a zero-year period (the intervention year) and a two-year postintervention period. Thus, for patients whose intervention year was 2004, the period studied was 2002-2006 and patients undergoing treatment in 2005 were studied from 2003-2007.

\section{Patient and Control Data on Benefits Received Due to Work Impairment}

Outcome data was acquired from Statistics Denmark, which is officially responsible for gathering data from administrative registries in Denmark. The aggregated register named Coherent Social Statistics contains records on the number of days with benefits for the registered population. Data are tallied once a year and cover a maximum of 360 days. Short descriptions of the benefits are given below.

\section{The Sickness Benefits Statistics Register}

Sick leave up to 14 days is paid by the employer. For sick leave over 14 days and up to 52 weeks, the municipality reimburses the benefit paid by the employer. When the worker is diagnosed with a chronic disease, the first 14 days of sick leave are also reimbursed by the municipality. Sick leave can, after a reassessment, be prolonged for another 52 weeks. Only sick leave days that are reimbursed are registered and tallied.

\section{The Unemployment Statistics Register}

To receive unemployment benefits, a person must be a member of the union unemployment insurance system and must be available to work on the labor market. To be entitled to unemployment financial compensation, the person must have been employed for at least 52 weeks within the last three years. All unemployment days are registered and tallied.

\section{The Social Pensions Statistics}

Disability pension can be awarded if a social worker determines that a person's ability to work is permanently impaired, that this person is unable to function without support and that the person has no prospects for improvement. Medical records and a professional assessment of the impairment must be obtained from a general practitioner, a specialist or a hospital. All days with disability pension are registered and tallied.

\section{Ethics}

The study was registered with the Danish Data Protection Agency. Because the study was non-invasive, receiving approval from the Danish National Committee on Biomedical Research Ethics was not necessary. All patients were informed in writing about the data gathered, and all consented to participate.

\section{Statistical analysis}

Data were analyzed using PASW (IBM-SPSS) version 18. The mean values $(\mathrm{M})$ and standard deviations (SD) of the number of days on sick leave, unemployment and disability pension were calculated for the patient and the control groups.

Independent t-tests were performed for the difference in number of days on sick leave, unemployment and disability pension between the control group and the patient groups at the two-year pre-intervention and the two-year post-intervention mark. Levene's test was used to test the homogeneity of variance. Groups with unequal variance were corrected.

Paired t-tests were conducted to evaluate the significance of changes in number of days with sick leave, unemployment and disability pension within the patient groups and the control group for the two-year pre and post comparison. The percent change and effect size (ES) were calculated. Effect sizes were calculated using the formula: $\mathrm{ES}=\left(\mathrm{mean}_{\mathrm{pre}}-\right.$

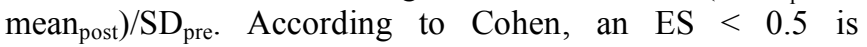
considered small, an $\mathrm{ES}=0.5$ to 0.8 is moderate, and an $\mathrm{ES}>$ 0.8 is large.

Change in number of days with sick leave, unemployment and disability pension over the two-year pre and post period were calculated. The differences in change of days with sick leave and unemployment between groups were analyzed with ANCOVA. The covariate in the analysis was the baseline level of days with sick leave and unemployment (two-year pretreatment), respectively. The differences in change of days of disability pension between groups were tested with ANOVA. 
Significant results in the ANCOVA and ANOVA were followed by planned contrasts to evaluate the significance of differences between the groups.

\section{RESULTS}

Of the 747 patients included in the study, 216 did not show up for treatment and 531 patients completed treatment. Tables 2-4 show the statistics for between-group t-tests, within group t-tests and ANCOVA. Fig. (2) shows the course of sick leave, unemployment and disability pension over all eight years for three groups. Fig. (3) shows the cumulative number of days on social security benefits for the
25 patients registered with a disability pension two years after treatment ended.

\section{The Control Group}

The control group served as a comparison baseline. Table 3 shows the average number of days with sick leave, unemployment and disability pension for the two-year pre and post-treatment, as well as the changes (differences) in the two-year pre and post comparison. Controls had a significant increase in sick leave and disability pension in the two-year pre and post comparison (see Table 3 ).

Table 2. Differences in Days with Sick Leave, Unemployment and Disability Pension Between Patient Groups and Control Group and Internally Between Patient Groups

\begin{tabular}{|c|c|c|c|c|c|c|}
\hline & \multicolumn{3}{|c|}{ Two-Year Pre } & \multicolumn{3}{|c|}{ Two-Year Post } \\
\hline Completer $v s$ control & $10.3 *$ & 4.4 & $<.000$ & $15.6^{*}$ & 5.1 & $<.000$ \\
\hline No-show $v s$ control & $4.4^{*}$ & 1.7 & 0.086 & $-1,9^{*}$ & 3.7 & $<.000$ \\
\hline \multicolumn{7}{|l|}{ Unemployment } \\
\hline Completer $v s$ control & $4.9^{*}$ & 2.2 & $\mathbf{0 . 0 3 0}$ & $1.8^{* *}$ & 1.1 & 0.278 \\
\hline No-show $v s$ control & $0.5^{* *}$ & 0.2 & 0.871 & $9.6^{*}$ & 2.7 & 0.008 \\
\hline Completer $v s$ no-show & $4.4 *$ & 1.2 & 0.215 & $-7.8 *$ & -1.9 & 0.053 \\
\hline Completer vs no-show & $0.0 * *$ & 0.0 & 0.998 & $0.1 * *$ & 0.0 & 0.992 \\
\hline
\end{tabular}

*Equal variances not assumed and df corrected.

$* *$ Equal variance assumed and df not corrected.

Table 3. Changes in Days with Sick Leave, Unemployment and Disability Pension in the Patient Groups and the Control Group Over the Two-Year Pre and Post Treatment Period

\begin{tabular}{|c|c|c|c|c|c|c|c|c|}
\hline \multicolumn{9}{|l|}{ Sick Leave } \\
\hline No-show & 9.8 & $(37.6)$ & 27.1 & $(78.2)$ & $176.8 \%$ & 0.46 & 3.0 & 0.003 \\
\hline Control & 5.4 & $(31.7)$ & 7.5 & $(37.7)$ & $38.9 \%$ & 0.07 & 5.4 & $<.000$ \\
\hline Completer & 13.9 & $(51.1)$ & 10.1 & $(41.1)$ & $-27.4 \%$ & 0.07 & -1.5 & 0.137 \\
\hline No-show & 9.5 & $(41.1)$ & 17.9 & $(53.1)$ & $89.4 \%$ & 0.21 & 1.9 & 0.062 \\
\hline Control & 9.0 & $(38.9)$ & 8.3 & $(37.4)$ & $-8.2 \%$ & 0.02 & -1.9 & 0.064 \\
\hline \multicolumn{9}{|c|}{ Disability Pension } \\
\hline
\end{tabular}


Table 4. ANCOVA*, ANOVA** and Planned Contrasts Evaluating Differences in Change in Number of Days with Sick Leave, Unemployment and Disability Pension Between the Groups

\begin{tabular}{|c|c|c|c|c|}
\hline $\begin{array}{c}\text { Two-Year Pre and } \\
\text { Two-Year Post Comparison }\end{array}$ & $\boldsymbol{F}$ & $\boldsymbol{p}$ & Contrast & $\boldsymbol{p}$ \\
\hline \hline Sick leave* & 60.5 & $<.001$ & & \\
\hline Completer $v s$ control & & & 15.8 & $<.001$ \\
\hline No-show $v s$ control & & & 19.8 & $<.001$ \\
\hline Completer $v s$ no-show & & & 4.0 & 0.235 \\
\hline Unemployment* & 8.7 & $<.001$ & & \\
\hline Completer $v s$ control & & & 1.1 & 0.501 \\
\hline No-show $v s$ control & & & 10.8 & $<.001$ \\
\hline Completer $v s$ no-show & & & 9.7 & $\mathbf{0 . 0 0 2}$ \\
\hline Disability pension** & 4.6 & $\mathbf{0 . 0 1 0}$ & & \\
\hline Completer $v s$ control & & & 4.1 & $\mathbf{0 . 0 1 0}$ \\
\hline No-show $v s$ control & & & 4.1 & 0.102 \\
\hline Completer $v s$ no-show & & & -0.1 & 0.982 \\
\hline
\end{tabular}

* Baseline number of days (two-year pre treatment) with sick leave and with unemployment included as a covariate in ANCOVA. ** Baseline number of days (twoyear pre treatment) with disability pension not included as a covariate due to a significant interaction in test of regression of homogeneity.

\section{The Completer Patients}

Between group t-tests showed that completer patients had significantly more days with sick leave and unemployment two years before treatment and significantly more days on sick leave two years after treatment than the control group (see Table 2). Paired t-tests showed that completer patients had a significant increase in disability pension in the twoyear pre and post comparison (see Table 3). ANCOVA showed that the increase in sick leave days and days on disability pension in the completer group was significantly larger than the increase in the control group (see Table 4). Thus, despite the psychotherapeutic treatment, sick leave and disability pension increased significantly compared to the control group.

\section{The No-Show Patients}

T-tests between groups showed that no-show patients did not significantly differ from controls with regard to number of days with sick leave or unemployment two years prior treatment, but two years after treatment no-show patients had significantly more sick leave and unemployment days than the control group (see Table 2). A paired t-test showed that no-show patients had a significant increase in sick leave and disability pension in the two-year pre and post comparison (see Table 3). ANCOVA showed that the increase in sick leave and unemployment was significantly larger for noshow patients than for the control group in the two-year pre and post comparisons and that the increase in unemployment was also significantly different from completer patients, whose unemployment days decreased (see Table 4). Thus, in accordance with our expectations, no treatment was associated with an increase in sick leave and unemployment.
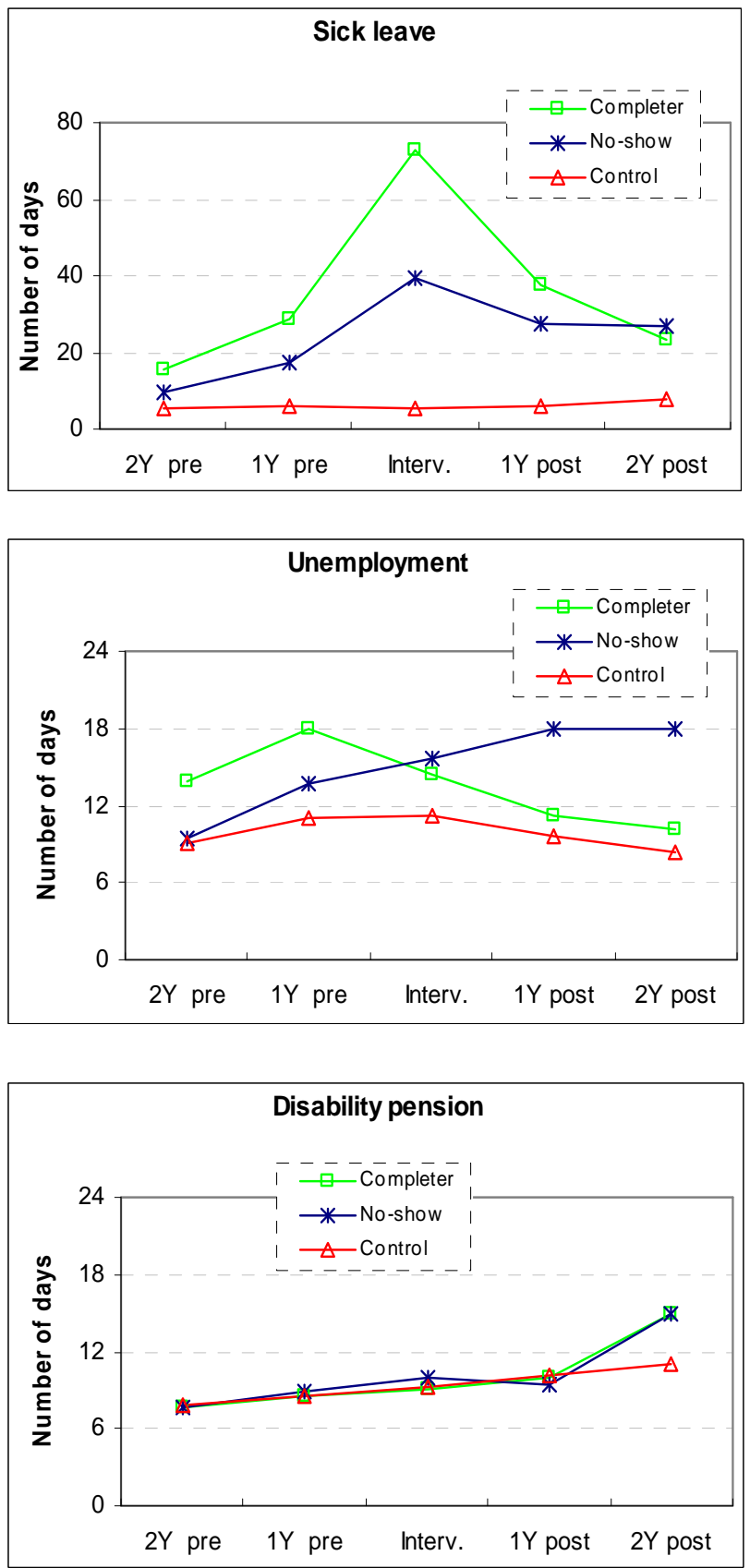

Fig. (2). Average number of days with sick leave, unemployment and disability pension per year before and after intervention for the three groups.

\section{DISCUSSION}

The aim of this study was to investigate the long-term effects of psychotherapy on occupational functioning. The study was based on registered sick leave, unemployment and disability pension records covering a five-year period. According to our results, psychotherapy was not followed by a reduction, but rather an increase in the number of days 
Benefits for $\mathbf{2 5}$ completer patients with disability pension two-year post intervention

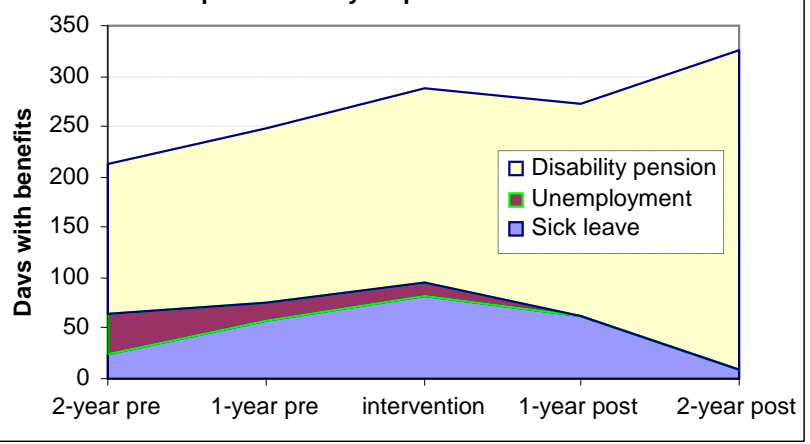

Fig. (3). Distribution of days with social security benefits for the 25 completer patients who had a disability pension at the two-year post intervention.

patients spent on sick leave and disability pension, while unemployment remained unchanged compared to the control group. This result is in contrast to the findings of previous studies on sick leave. One possible reason for the difference can perhaps be explained due to methodological differences. In the ten studies referred to in the introduction, a short or unsymmetrical period of observation was used and all of the studies recorded sick leave days around referral/intake, a point at which the severity of the illness was probably peaking. When the numbers were compared to some point after treatment ended, they inevitably indicated a decline. The fact that the present study utilized a longer, more symmetrical comparison period may explain the strikingly different results compared to previous studies. Thus, the results of our study suggest that existing intervention studies on sick leave may provide an overly optimistic impression of the benefits of psychotherapy.

\section{Sick Leave}

At least three possible explanations exist to explain why therapy did not reduce sick leave. First, patients referred to Stolpegaard Psychotherapy Centre largely suffer from longlasting conditions rather than temporary states [8]. Throughout the five-year period covered in this study, completer patients had significantly more sick leave days than the control group, which also suggests that their problems were of a more chronic nature. The second explanation is that the highly efficient, specialized Danish labor market does not accommodate the special needs of people with mental disorders well. A Danish white paper on mental health and work found that people with mental health problems on sick leave have problems returning to work [2]. The third explanation relates to the focus of psychotherapy. Typically, psychotherapy is not aimed at helping patients strengthen their occupational functions, but rather at relieving the patients' subjective experience of distress [6]. It could, however, be argued that further parameters than reduction of symptoms need to be considered as goals for evidence-based treatment [34]. For example, it has been suggested that quality of life, functional health status, and social and occupational functioning might be equally appropriate and relevant areas to measure as patient symptoms $[34,35]$.

\section{Unemployment}

In contrast to our sick leave results, the high unemployment rate for people with mental disorders is in accordance with other studies in the literature. The results regarding changes in unemployment after treatment are more complex. As the Fig. (2) depicts, unemployment decreased for completer patients but increased for no-shows, suggesting that intervention did help. However, when comparing changes in completer patients to the control group, which also meant taking labor market developments into account, no significant decreases was observed (see Table 4 for adjusted values). In comparing our results to the literature, we found other studies that investigate the impact of psychotherapeutic treatment on employment status: Wang et al. compared a treatment as usual to an active outreach and care management program for depressed workers [27]; Nygreen et al. investigated an occupational intervention normally applied to patients with severe illness and tested it on a group with common mental disorders [28]; Well et al. investigated quality care (psychotherapy) compared to traditional primary care for patients with depression [25]; Proudfoot et al. investigated cognitive behavioral therapy aimed at improving the occupational ability of individuals with minor mental problems and who were experiencing long-term unemployment [24]. These studies found that applied intervention had a significant impact on work status. Thus, our results conflict with previous research on change in employment status after treatment. One possible explanation for this discrepancy is that these four studies compared employment status at intake with employment status at some point during the 6-12 month follow-up, while we applied a symmetrical two-year pre and post treatment period for comparison. Another explanation is that in three out of the four employment studies, the primary purpose was to strengthen occupational functionality, while our study primarily was aimed at relieving psychological distress. Thus, the effects of developing and applying the right intervention strategy or program would be highly beneficial $[11,23,24]$.

\section{Disability Pension}

The rise in disability pension that we observed after completion of treatment was surprising, because our patients were not diagnosed with a severe mental illness. Fig. (3) shows that the 25 completer patients who received disability pension two years after treatment had previously had a period of sick leave and/or unemployment. Thus, the interdependence between disability pension, sick leave and unemployment is a relevant methodological issue [2, 31, 32] when evaluating the effect of an intervention. The most straightforward explanation for the increase in disability pension is that, for a number of patients on long-term sick leave, the psychiatric treatment was instigated after a prolonged period where they were unable to work. If medical and mental health assessments regarding the patient's ability to work after psychotherapy remain negative, disability pension can be perceived as the last resort. Other studies 
have suggested a similar connection between sick leave, psychiatric disorders and disability pension awards in Sweden $[31,32]$. Gustafsson et al. concluded that a medical assessment did not improve people's chances of returning to work, but rather served as a justification for receiving a disability pension [32]. For our patients and other patients with non-psychotic mental disorders, a disability pension will most likely preclude future treatment [5].

\section{CONCLUSION AND IMPLICATIONS OF THE STUDY}

This five-year study showed that while unemployment remained unchanged, the psychotherapeutic treatment of patients with non-psychotic mental disorders did not prevent an increase in the number of days on sick leave and disability pension. We proposed a number of possible explanations for these results. The most important of which is that the psychotherapy provided was not designed to strengthen or reclaim occupational functionality, but to relieve psychological distress. Others have criticized the practice of treating only symptoms and suggest that to improve psychotherapy, functional outcome should also be targeted [34, 35]. It has been shown that unemployment often leads to secondary stressors, like worrying, financial problems and family difficulties [36]. Studies have suggested that employment has markedly positive effects on mental health and reduces psychological stress [36]. Therefore, intervention may be improved further by taking on a broader perspective regarding the kind of problems that should be addressed and the possible solutions for solving these problems - both for patients who complete treatment and for patients who choose non-attendance as their way of coping [37-39].

\section{LIMITATIONS AND STRENGTHS}

Our study has a number of limitations. First, only a rough time demarcation could be applied to the period of treatment and days with sick leave, unemployment and disability, because the register data only comprised amounts calculated on an annual basis. Second, an unknown number of patients and control subjects were most likely not a member of the union unemployment insurance system, which means they were not registered as unemployed. Obtaining complete unemployment records from both the unemployment insurance fund and outside sources would have been preferable. Third, the occurrence and duration of sick leave, unemployment and disability pension are sensitive to economic and political regulation [2, 5, 40], which is why our results must be looked at within the context of the social security system and political regulation.

The validity of our study results, however, is likely to be higher than that of most other studies for three reasons. First, our data on occupational status were collected from highly reliable administrative registries over a period of five years. Second, we used a matched control group to account for changes in occupational status in the general population. Third, our study comprised data on three interconnected measures of occupational function: sick leave, unemployment and disability pension. Consequently, this study provided a comprehensive account of the impact of psychotherapy on the occupational functioning of patients with non-psychotic mental problems. Still, further studies are needed to support or challenge our findings.

\section{CONFLICT OF INTEREST}

The authors confirm that this article content has no conflict of interest.

\section{ACKNOWLEDGEMENTS}

This research was funded by a grant from the Danish foundation TrygFonden for the research project "Outcomes in Psychotherapeutic Treatment".

\section{REFERENCES}

[1] Hensing G, Wahlstrom R. Swedish council on technology assessment in health care (SBU). Chapter 7. Sickness absence and psychiatric disorders. Scand J Public Health Suppl 2004; 63:15280 .

[2] Borg W, Nexø MA, Kolte IV, Andersen MF. Resumé og sammenfatning af hvidbog om mentalt helbred, sygefravær og tilbagevenden til arbejde. Det Nationale Forskningscenter for Arbejdsmiljø, 2010.

[3] Butterworth P, Leach LS, Pirkis J, Kelaher M. Poor mental health influences risk and duration of unemployment: a prospective study. Soc Psychiatry Psychiatr Epidemiol 2012; 47(6): 1013-21.

[4] Organisation for Economic Co-operation and Development. Transforming disability into ability. OECD Publication Service; 2003.

[5] Birket-smith M, Eplov LF. Psykiske lidelser og førtidspensionering. Socialministeriet, 2007.

[6] Bergin A, Garfield S, Lambert MJ. Bergin and Garfield's handbook of psychotherapy and behavior change. 5 ed. Wiley, 2004.

[7] Butler AC, Chapman JE, Forman EM, Beck AT. The empirical status of cognitive-behavioral therapy: a review of meta-analyses. Clin Psychol Rev 2006; 26:17-31.

[8] Fenger M. Psychotherapy: Attendance and effects on utilisation of health care services and occupational functioning. University of Copenhagen 2012.

[9] Lazar A, Sandell R, Grant J. Do psychoanalytic treatments have positive effects on health and health care utilization? Further findings of the Stockholm Outcome of Psychotherapy and Psychoanalysis Project (STOPPP). Psychother Res 2006; 16: 51-66.

[10] Alexanderson K, Hensing G. More and better research needed on sickness absence. Scand J Public Health 2004; 32: 321-3.

[11] Harvey SB, Henderson M, Lelliott P, Hotopf M. Mental health and employment: much work still to be done. Br J Psychiatry 2009; 194: 201-3.

[12] Sobocki P, Jonsson B, Angst J, Rehnberg C. Cost of depression in Europe. J Ment Health Policy Econ 2006; 9: 87-98.

[13] Mintz J, Mintz LI, Arruda MJ, Hwang SS. Treatments of depression and the functional capacity to work. Arch Gen Psychiatry 1992; 49:761-8.

[14] Nieuwenhuijsen K, Bultmann U, Neumeyer-Gromen A, Verhoeven $\mathrm{AC}$, Verbeek $\mathrm{JH}$, van der Feltz-Cornelis CM. Interventions to improve occupational health in depressed people. Cochrane Database Syst Rev 2008; 2: CD006237.

[15] Simon GE, Revicki D, Heiligenstein J, et al. Recovery from depression, work productivity, and health care costs among primary care patients. Gen Hosp Psychiatry 2000; 22:153-62.

[16] van der Klink JJ, Blonk RW, Schene AH, van Dijk FJ. Reducing long term sickness absence by an activating intervention in adjustment disorders: a cluster randomised controlled design. Occup Environ Med 2003; 60: 429-37.

[17] Huibers MJ, Beurskens AJ, van Schayck CP, et al. Efficacy of cognitive-behavioural therapy by general practitioners for unexplained fatigue among employees: randomised controlled trial. Br J Psychiatry 2004; 184: 240-6.

[18] Bakker IM, Terluin B, van Marwijk HW, et al. A clusterrandomised trial evaluating an intervention for patients with stressrelated mental disorders and sick leave in primary care. PLoS Clin Trials 2007; 2: e26. 
[19] Brouwers EP, de Bruijne MC, Terluin B, Tiemens BG, Verhaak PF. Cost-effectiveness of an activating intervention by social workers for patients with minor mental disorders on sick leave: a randomized controlled trial. Eur J Public Health 2007; 17: 214-20.

[20] Knekt P, Lindfors O, Laaksonen MA, Raitasalo R, Haaramo P, JÃarvikoski A. Effectiveness of short-term and long-term psychotherapy on work ability and functional capacity - A randomized clinical trial on depressive and anxiety disorders. J Affect Disord 2008;107: 95-106.

[21] Stenlund T, Ahlgren C, Lindahl B, et al. Cognitively oriented behavioral rehabilitation in combination with Qigong for patients on long-term sick leave because of burnout: REST--a randomized clinical trial. Int J Behav Med 2009;16: 294-303.

[22] Linden M, Zubragel D, Bar T. Occupational functioning, sickness absence and medication utilization before and after cognitivebehaviour therapy for generalized anxiety disorders. Clin Psychol Psychother 2011; 18(3): 218-24.

[23] Arnfred S, Eplov LF, Korsbek L, Petersen L, Olander M. Rehabilitering ved angst og depression. In: Eplov LF, Korsbek L, Petersen L, Olander M, editors. Psykiatrisk \& psykosocial rehabilitering, en recoveryorienteret tilgang. 2010.

[24] Proudfoot J, Gray J, Carson J, Guest D, Dunn G. Psychological training improves mental health and job-finding among unemployed people. Int Arch Occup Environ Health 1999; 72 Suppl: S40-2.

[25] Wells KB, Sherbourne C, Schoenbaum M, et al. Impact of disseminating quality improvement programs for depression in managed primary care: a randomized controlled trial. JAMA 2000; 283: $212-20$.

[26] Schoenbaum M, Unutzer J, McCaffrey D, Duan N, Sherbourne C, Wells KB. The effects of primary care depression treatment on patients' clinical status and employment. Health Serv Res 2002; 37:1145-58.

[27] Wang PS, Simon GE, Avorn J, et al. Telephone screening, outreach, and care management for depressed workers and impact on clinical and work productivity outcomes: a randomized controlled trial. JAMA 2007; 298:1401-11.

[28] Nygren U, Markstrom U, Svensson B, Hansson L, Sandlund M. Individual placement and support - a model to get employed for people with mental illness - the first Swedish report of outcomes. Scand J Caring Sci 2011; 25: 591-8.

[29] Sorvaniemi M, Helenius H, Salokangas RK. Factors associated with being granted a pension among psychiatric outpatients with major depression. J Affect Disord $2003 ; 75: 43-8$.
[30] Mykletun A, Overland S, Dahl AA, et al. A population-based cohort study of the effect of common mental disorders on disability pension awards. Am J Psychiatry $2006 ; 163: 1412-8$.

[31] Vaez M, Rylander G, Nygren A, Asberg M, Alexanderson K. Sickness absence and disability pension in a cohort of employees initially on long-term sick leave due to psychiatric disorders in Sweden. Soc Psychiatry Psychiatr Epidemiol 2007;42: 381-8.

[32] Gustafsson K, Lundh G, Svedberg P, Linder J, Alexanderson K, Marklund S. Disability, sickness, and unemployment benefits among long-term sickness absentees five years before, during, and after a multidisciplinary medical assessment. J Multidiscip Healthc 2011; 4: 25-31.

[33] Short ME, Goetzel RZ, Pei X, et al. How accurate are self-reports? Analysis of self-reported health care utilization and absence when compared with administrative data. J Occup Environ Med 2009; 51: 786-96.

[34] Perkins R. What constitutes success? The relative priority of service users' and clinicians' views of mental health services. Br J Psychiatry 2001;179: 9-10.

[35] McKnight PE, Kashdan TB. The importance of functional impairment to mental health outcomes: a case for reassessing our goals in depression treatment research. Clin Psychol Rev 2009; 29: 243-59.

[36] McKee-Ryan F, Song Z, Wanberg CR, Kinicki AJ. Psychological and physical well-being during unemployment: a meta-analytic study. J Appl Psychol 2005; 90: 53-76.

[37] Self R, Oates P, Pinnock-Hamilton T, Leach C. The relationship between social deprivation and unilateral termination (attrition) from psychotherapy at various stages of the health care pathway. Psychol Psychother 2005; 78(Pt 1): 95-111.

[38] Laaksonen E, Martikainen P, Lallukka $\mathrm{T}$, et al. Economic difficulties and common mental disorders among Finnish and British white-collar employees: the contribution of social and behavioural factors. J Epidemiol Community Health 2009; 63: 43946.

[39] Molarius A, Berglund K, Eriksson C, et al. Mental health symptoms in relation to socio-economic conditions and lifestyle factors-a population-based study in Sweden. BMC Public Health 2009; 20; 9: 302

[40] Lund T, Christensen KB, Vaez M, et al. Differences in sickness absence in Sweden and Denmark: the cross national HAKNAK study. Eur J Public Health 2009;19: 343-9. 